\title{
Actividades productivas de la costa tropical granadina
}

Ana Belén García Muñoz | antropóloga

URL de la contribución <www.iaph.es/revistaph/index.php/revistaph/article/view/3571>

\section{RESUMEN}

El sistema productivo de una comarca se encuentra unido intrínsecamente a diversos aspectos que lo definen y le otorgan su propia identidad. Las actividades diarias que se desarrollan con cotidianidad a lo largo del ciclo anual están adheridas a factores tales como la climatología, la orografía del terreno, los recursos naturales existentes, así como el uso realizado por las civilizaciones que han ocupado el territorio a lo largo de los siglos.

La costa tropical de Granada es una comarca caracterizada por una orografía abrupta y un clima de temperaturas suaves durante todo el año. Ambos elementos han favorecido un microclima el cual ha ayudado al desarrollo de tipologías de cultivo de frutos subtropicales que en otras zonas de la provincia habrían sido prácticamente imposibles. Entre las plantaciones más significativas y arraigadas culturalmente en la zona se encuentra la caña de azúcar, cultivo que constituyó un gran estímulo socioeconómico a la comarca, dejando numerosos reductos de patrimonio inmueble como ingenios o trapiches. Por otra parte las plantaciones de cultivo tropical se ubican en municipios tales como Almuñécar, Los Guájares, Motril, Salobreña, Itrabo, Lentejí, Jete, Molvízar y Vélez de Benaudalla. Los cultivos suelen establecerse en los márgenes de los ríos o en bancales ubicados bajo las faldas de las estribaciones de las sierras. La interconexión entre sus pobladores y el mar ha sido de vital de importancia para la economía local, desarrollándose labores vinculadas al sector pesquero. Es el caso de Motril, un puerto con gran actividad.

\section{Palabras clave}

Actividad socioeconómica | Caña de azúcar | Costa de Granada | Cultivo industrial | Cultivo subtropical | Identidad cultural | Pesca | Paisaje cultural | 


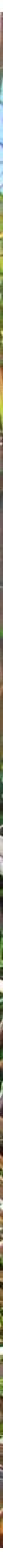

Mondero | foto Ana Belén García Muñoz, autora de todas las imágenes que ilustran este artículo 
La costa tropical de Granada es un territorio que se extiende en el extremo sur de esta provincia. Limita al oeste con Málaga y al este con Almería, mientras que al norte lo hace con las comarcas de la Alpujarra, Valle de Lecrín y Alhama. Abarca un territorio de $786,88 \mathrm{~km}^{2}$, el cual se subdivide en diecisiete municipios de los cuales nueve conforman la línea litoral y ocho de ellos se hallan en el interior. Los municipios que conforman la comarca son: Albondón, Albuñol, Almuñécar, Los Guájares, Gualchos, Ítrabo, Jete, Lentegí, Lújar, Molvízar, Motril, Otívar, Polopos, Rubite, Salobreña, Sorvilán y, finalmente, Vélez de Benaudalla. La cabecera de partido lo constituye el municipio de Motril, constituyéndose como el más extenso y el que aglutina mayor población. Se trata pues del centro administrativo y socioeconómico de la comarca, distinguiéndose por su gran actividad en cuanto al tráfico marítimo se refiere, pues Motril es el puerto principal de la provincia de Granada y núcleo de un gran movimiento de interrelaciones comerciales.

La orografía del terreno y la climatología son dos aspectos que históricamente han servido para componer un entramado de sistemas productivos que a día de hoy siguen vigentes de algún modo. El paisaje abrupto que identifica a la comarca, en la cual las estribaciones de Sierra Nevada mueren prácticamente en el mar Mediterráneo, ha definido un sistema de cultivo en bancales, aprovechando así las vertiginosas laderas que delimitan el relieve. Por otra parte, la climatología es uno de los aspectos que mejor repercuten en el desarrollo de cultivos de frutos tropicales, pues el alto grado de humedad y la temperatura templada a lo largo de todo el año facilitan el crecimiento de estos frutos que en la actualidad representan gran parte de la actividad agrícola en la comarca. Finalmente, mencionar la importancia del paso del río Guadalfeo, el cual nace en Sierra Nevada y desemboca en la costa granadina. Dicho tránsito ha propiciado históricamente el desarrollo de la fértil vega en la comarca.

Tradicionalmente la actividad socio-económica se ha llevado a cabo en las zonas de vega; sin embargo, en los últimos años la tendencia apunta sobre una transformación del paisaje en el cual se están desarrollando el auge de la edificación inmobiliaria con fines turísticos, la expansión de la agricultura bajo plástico y el cultivo de frutos subtropicales.

La fertilidad de los campos y el acceso al agua han permitido que la comarca haya sido un área caracterizada por la actividad agrícola a lo largo de los siglos. Entre las plantaciones más significativas y arraigadas culturalmente en la zona se encuentra la caña de azúcar, cultivo que constituyó un gran estímulo socioeconómico para la comarca, dejando numerosos reductos de patrimonio inmueble como ingenios o trapiches (espacio de tratamiento de la caña para la obtención del azúcar). Hoy día quedan pocos espacios agrícolas donde encontrar dicho cultivo, pues la crisis de la caña provocó prácticamente el abandono de esta industria. En la actualidad pueden hallarse 
algunos espacios de cañavera para el consumo familiar de la pulpa de la caña. Sin embargo, a mediados del siglo XX se introdujo el cultivo de frutos subtropicales, los cuales se han constituido como una de las señas de identidad de la comarca alcanzando altos índices de producción de la cosecha, destacando la recolección de chirimoyas, aguacates, mangos o nísperos, entre otros. Los cultivos bajo plástico son otra de las formas que más se han integrado en el paisaje en la comarca, aprovechando la óptima climatología que permite un gran ritmo de producción de hortalizas como el pepino y el tomate. En torno a este sistema productivo ha aparecido en las últimas décadas un entramado laboral que repercute positivamente en la actividad socioeconómica de la zona.

El aprovechamiento de los recursos marinos ha sido otra de las actividades características de los municipios de la franja costera; tanto es así, que la pesca se constituye como otro de los sectores más arraigados en algunos núcleos costeros.

En el puerto de Motril es donde se produce una mayor actividad comercial y pesquera, pues se considera como uno de los Puertos de Interés General del Estado. La artesanía de la pesca conlleva un conglomerado de actividades y saberes que se desarrollan en varios espacios, como la actividad en la lonja o las prácticas artesanales derivadas de la pesca tales como el arreglo de redes o fabricación de aparejos usados en las diversas técnicas. Por otra parte, desde el puerto existe un vasto transporte marítimo que aglutina un entramado de relaciones comerciales ligadas a la actividad industrial, tales como la química del metal, el papel, la conserva y manipulación de productos agrícolas.

La vegetación de esparto o cañavera, fibra procedente de la caña de azúcar, también propició la existencia de personas que se dedicaban a elaborar útiles de estos materiales para uso doméstico o agrícola. En la actualidad se trata de un reducto con escasa incidencia en el sistema económico-social y el uso de dichos instrumentos ha quedado sustituido por nuevos materiales derivados del plástico u otros compuestos.

La construcción y el sector inmobiliario son otros de los sectores que han prosperado a través del fomento del turismo regional e internacional en la comarca vinculado al turismo costero. Dicho desarrollo ha repercutido en las empresas ligadas al sector turístico: actividad hotelera, o la proliferación de nuevos conceptos de empresas unidas al turismo deportivo, como el golf, el surf, el buceo, el windsurf o la vela, etc.

El desarrollo económico de la comarca, particularmente en los municipios turísticos, ha provocado una clara recuperación y crecimiento demográfico, que había descendido en décadas anteriores. 


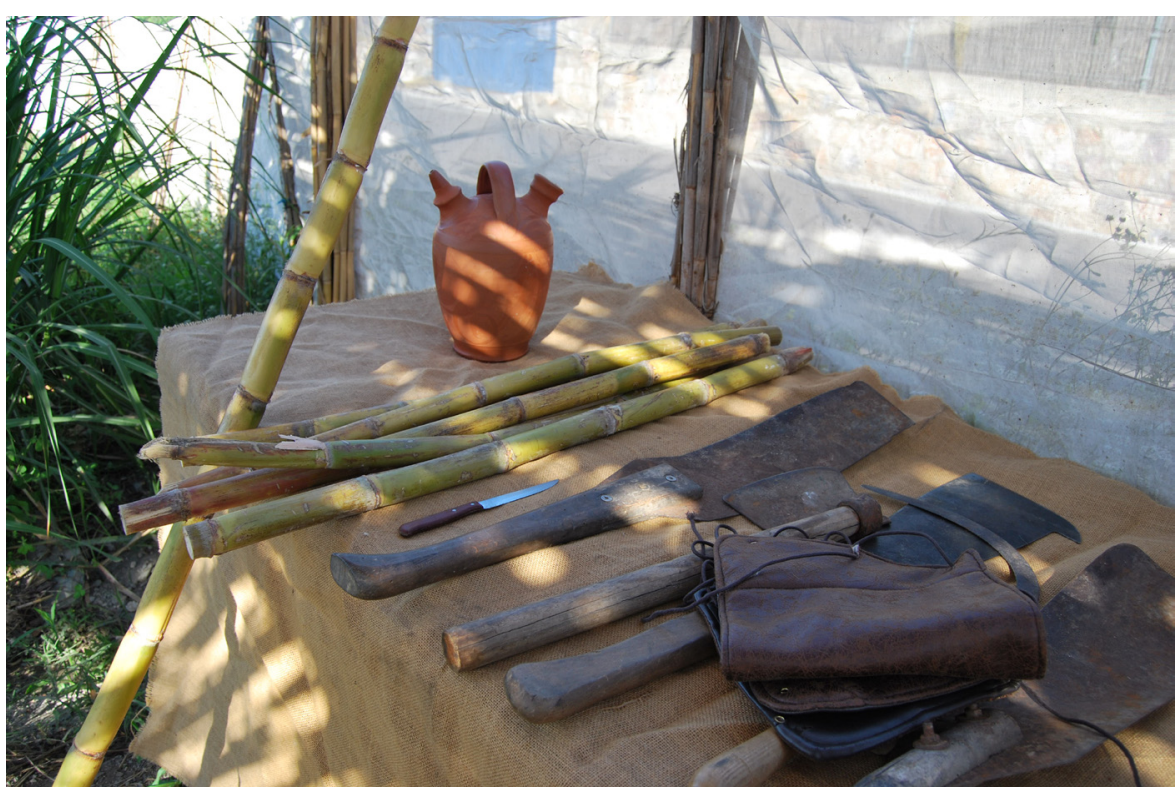

Herramientas para la zafra

\section{DEFINICIÓN DE LOS SISTEMAS MÁS INFLUYENTES EN LA ACTIVIDAD SOCIO-ECONÓMICA: EL CULTIVO DE LA CAÑA DE AZÚCAR EN MOTRIL}

Entre los cultivos tradicionales con mayor arraigo social e histórico en la comarca de la costa tropical de Granada destaca la caña de azúcar. La cultura árabe integró en el paisaje del litoral esta plantación, adaptándola fácilmente al paisaje, pues tanto el clima y la fertilidad de los valles en la que se sembraba propiciaron un desarrollo óptimo de la misma. En torno a este cultivo se expandieron numerosos centros de obtención de azúcar: los trapiches e ingenios, principalmente en el municipio de Motril, provocaron que se necesitara una gran cantidad de mano de obra constituyendo uno de los principales sectores económicos de la comarca.

Sin embargo, con el inicio del siglo XX, la caña de azúcar dejó de ser un cultivo rentable, produciéndose una grave crisis a consecuencia de la competitividad de la remolacha, así como la problemática de la degeneración de tipologías de cañas. Desde esta fecha hasta la guerra civil tiene lugar una cierta recuperación de los precios de la caña. Sin embargo este espejismo acaba en 1970, cuando la caña de azúcar comienza a decaer frente al avance de los cultivos de los frutos tropicales.

Hoy día el cultivo de la caña de azúcar y su manufactura para la extracción del azúcar ha desaparecido prácticamente. En el año 2006 cerró el último ingenio en el barrio de La Caleta, ubicado en el municipio de Salobreña. Aún existen algunos agricultores que mantienen la siembra de un pequeño espacio de cañaveral en sus fincas para el consumo propio, pues el jugo que se 

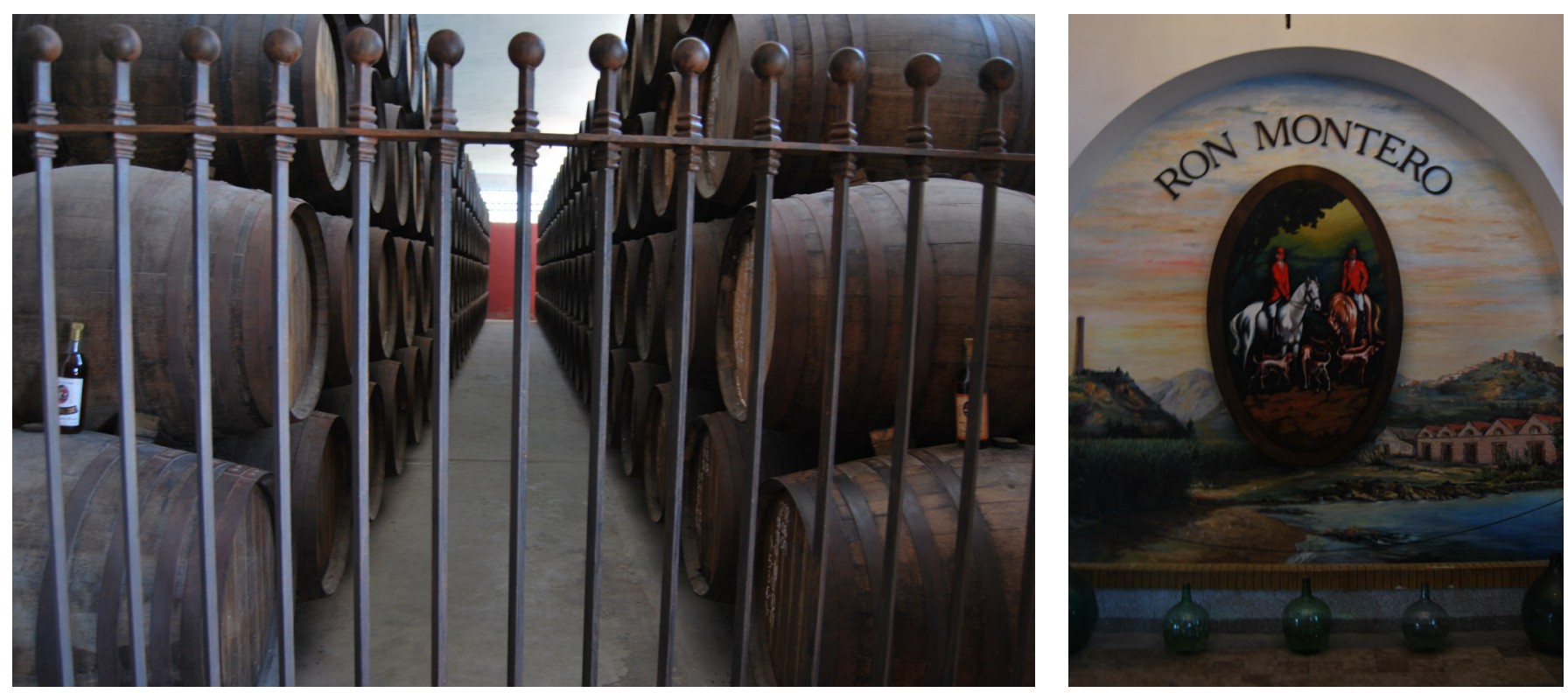

Bodega de ron

extrae masticando la pulpa es muy dulce y añorado por los habitantes del lugar. También existen varias reservas del cultivo, la Charca Suárez y la finca las Cañas, ambas espacio de interés cultural destinadas al turismo agroecológico, donde se organizan visitas guiadas para dar a conocer uno de los cultivos históricos más importantes de la costa granadina.

La industrialización del sector de la caña de azúcar a partir de los siglos XIX y XX y la integración de la actividad en la economía permitieron que florecieran otros subsectores que utilizaban dicha materia prima para otros menesteres que la obtención de azúcar, como la elaboración de aguardiente, el cual se obtenía de plantas ricas en sacarosa, elemento del que se obtiene el etanol y que, al mezclarse con agua, se convertía en esta bebida espirituosa y más tarde en la producción de ron. Existen referencias de la existencia de una fábrica de "rom" en las crónicas de Sebastián Miñano, en el Diccionario Geográfico Estadístico de España y Portugal en 1827: "Motril (Sexi Firmium Julium)...fábrica de salitre y de rom que no cede en calidad al mejor de la Jamaica". En 1847 se publica en la voz "Motril" del Diccionario de Pascual Madoz la noticia de la existencia de una fábrica de rom que se resiste a prosperar, la cual era propiedad Juan Buenaventura Vallés, catalán que obtuvo un premio en la Exposición Industrial Española en 1828. Pero no es hasta el siglo XX cuando se produce el máximo esplendor de la producción de ron por una familia azucarera. En 1929 nació el fundador de la bodega Ron Montero fundada en el año 1963. Francisco Montero procedía de una familia de gran tradición azucarera. Desde su infancia estuvo en contacto con la destilería Azucarera Montero, empresa familiar, que hoy día continúa elaborando aguardiente de caña. Actualmente la dirección de la bodega la adopta 
Andrea Martín Targa. El trabajo en la bodega no solo se centra en la producción de ron, sino que colabora con las instituciones en lograr revitalizar el interés cultural a través de la realización de rutas turísticas, gastronómicas, así como el Festival del Ron Montero en el cual se realizan talleres de coctelería, conciertos, pasacalles como la recreación de la fiesta de la Taramela, etc.

Hoy día aún se conserva incluso un ritual que conmemoraba el final de la cosecha, la cual se traducía como una forma de celebración de la prosperidad del ciclo anual del cultivo. Dicha festividad es conocida con el nombre de Taramela. Durante este día se hace una recreación de la fiesta de antaño en la cual todos los trabajadores que venían desde otras poblaciones a las labores de la recogida de caña, los monderos de las cañas y los tacheros, que eran las personas que trabajaban en los ingenios para la extracción del azúcar de la caña, adornaban sus carros con flores y las mulas eran engalanadas con la mejor talabartería que tuviesen.

\section{EL CULTIVO TROPICAL EN LA COSTA TROPICAL DE GRANADA}

La actividad agrícola se ubica a lo largo de un ancho margen entre la sierra y el litoral. Las plantaciones de cultivo tropical se hallan en municipios tales como Almuñécar, Los Guájares, Motril, Salobreña, Itrabo, Lentejí, Jete, Molvízar y Vélez de Benaudalla. Los cultivos suelen establecerse en los márgenes de los ríos o en bancales ubicados bajo las faldas de las estribaciones de las sierras.

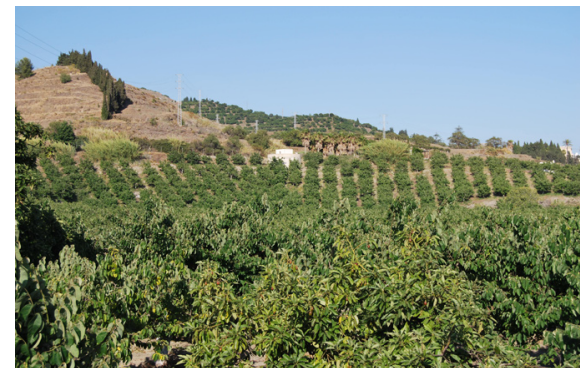

La recesión de la industria azucarera a mediados del siglo XX trajo consigo la aparición de un nuevo cultivo: el fruto tropical. La similitud de este espacio físico al de los países tropicales en cuanto a la climatología, caracterizada por temperaturas sin grandes oscilaciones y un alto grado de humedad, favoreció la adaptabilidad de dichos frutos integrándose en el paisaje de la costa granadina y llegando a instituirse como un símbolo de identidad comarcal, apadrinando así el apelativo de "costa tropical" en alusión a esta nueva variedad de cultivo. Cabe resaltar que la plantación de dichos frutos ya se desarrollaba en pequeños huertos familiares para el autoconsumo.

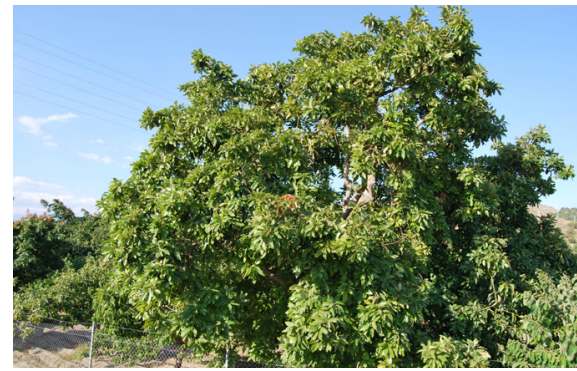

El fruto que representa en mayor grado a este sector es la chirimoya, que comenzó a comercializarse desde 1950 y fue catalogado en el año 2002 dentro de la Denominación de Origen Protegida. Una década más tarde se introdujo el aguacate.

El desarrollo socioeconómico y la integración paisajística que dichos cultivos han experimentado en las últimas décadas ha favorecido su constituCultivos tropicales ción como seña de identidad formando ya parte de la propia cultura de las 

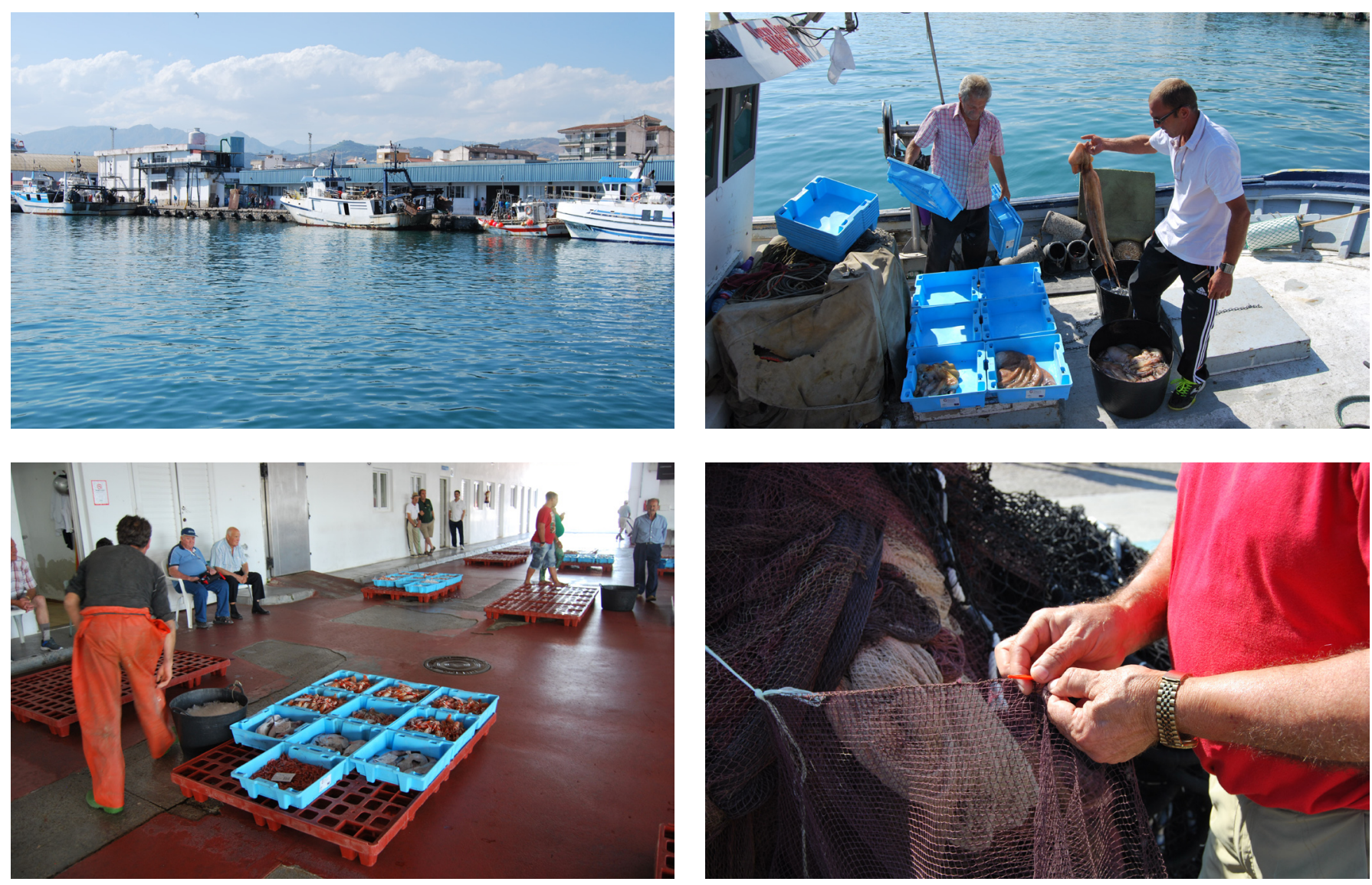

Puerto de Motril

gentes que habitan estas tierras y que poseen en su saber un conocimiento Embarcación de artes menores forjado por la faena en el campo, la adaptabilidad agrícola, el consumo famiLonja liar, etc.

\section{LA ACTIVIDAD PESQUERA EN EL PUERTO DE MOTRIL}

El emplazamiento estratégico de la costa granadina facilitó el asentamiento de diversas culturas que a través de los siglos se establecieron en estos parajes aprovechando la fertilidad de sus valles y el enclave marítimo que les proporcionaba un amplio abanico de recursos naturales. Los fenicios fueron una de las civilizaciones más florecientes en la zona, con una potente industria de salazón y exportación del garum. La amalgama de saberes, técnicas de pesca, gastronomía, etc. fueron constituyendo la identidad cultural de este territorio.

Hoy día la pesca se configura como uno de los sectores más significativos en algunos núcleos costeros de la comarca, produciéndose en torno a ella un 
fructífero mercado. Motril es uno de los puertos donde se produce una mayor actividad pesquera. Destaca la actividad de pequeñas empresas de carácter familiar, junto a la incesante actividad en la lonja y las actividades derivadas del oficio como el arreglo de redes y aparejos usados para la pesca.

Históricamente los pescadores del litoral granadino han destacado por el uso de artes de pesca tradicionales tales como el copo, la birorta del chanquete y el boliche. A principios del siglo XX se llevaban a cabo las técnicas del pincho (palangre de fondo) y la amarradera para capturar al pez espada. En las últimas décadas se fueron introduciendo las embarcaciones de artes menores. Algunas de las técnicas tradicionales han sido prohibidas por su actividad invasiva a la fauna marina; este es el caso de la técnica del copo, pesca que se realizaba desde la orilla con redes que los pescadores echaban al mar para posteriormente tirar con fuerza desde la orilla.

La gastronomía local también ha sido influenciada por la amplia gama de pescados y mariscos que se pescan en el puerto de Motril reproduciéndose un sinfín de recetas cuyo ingrediente básico es el pescado. Producto famoso por excelencia es la quisquilla de Motril, la cual alcanza altos precios en el mercado y es muy codiciada por su sabor. También las gambas y cigalas, o pescados como pescadillas, pargos, sargos, doradas, lubinas, pintarroja, sapos, etc. La salazón de pescado y las espichás (pescado secado al sol) son muy tradicionales en la zona.

El patrimonio pesquero se extiende a otros ámbitos de la cultura popular. El ritual de la Virgen del Carmen en el Varadero, población que se encuentra junto a las inmediaciones del puerto de Motril, es una celebración en la cual se reproducen una serie actividades en el puerto pesquero: desde la realización de la procesión marítima en la cual participan embarcaciones pesqueras, hasta una misa celebrada en el espacio de la lonja.

El sistema productivo de una comarca se identifica por las actividades diarias realizadas por sus pobladores que a través de los recursos naturales repercuten en la actividad socio-económica de la zona. En dicho entramado entran en juego una serie de variantes de diversa índole que con el devenir de los años reflejan un sistema delimitado por la climatología, la orografía, el patrimonio natural y el flujo constante de civilizaciones. 


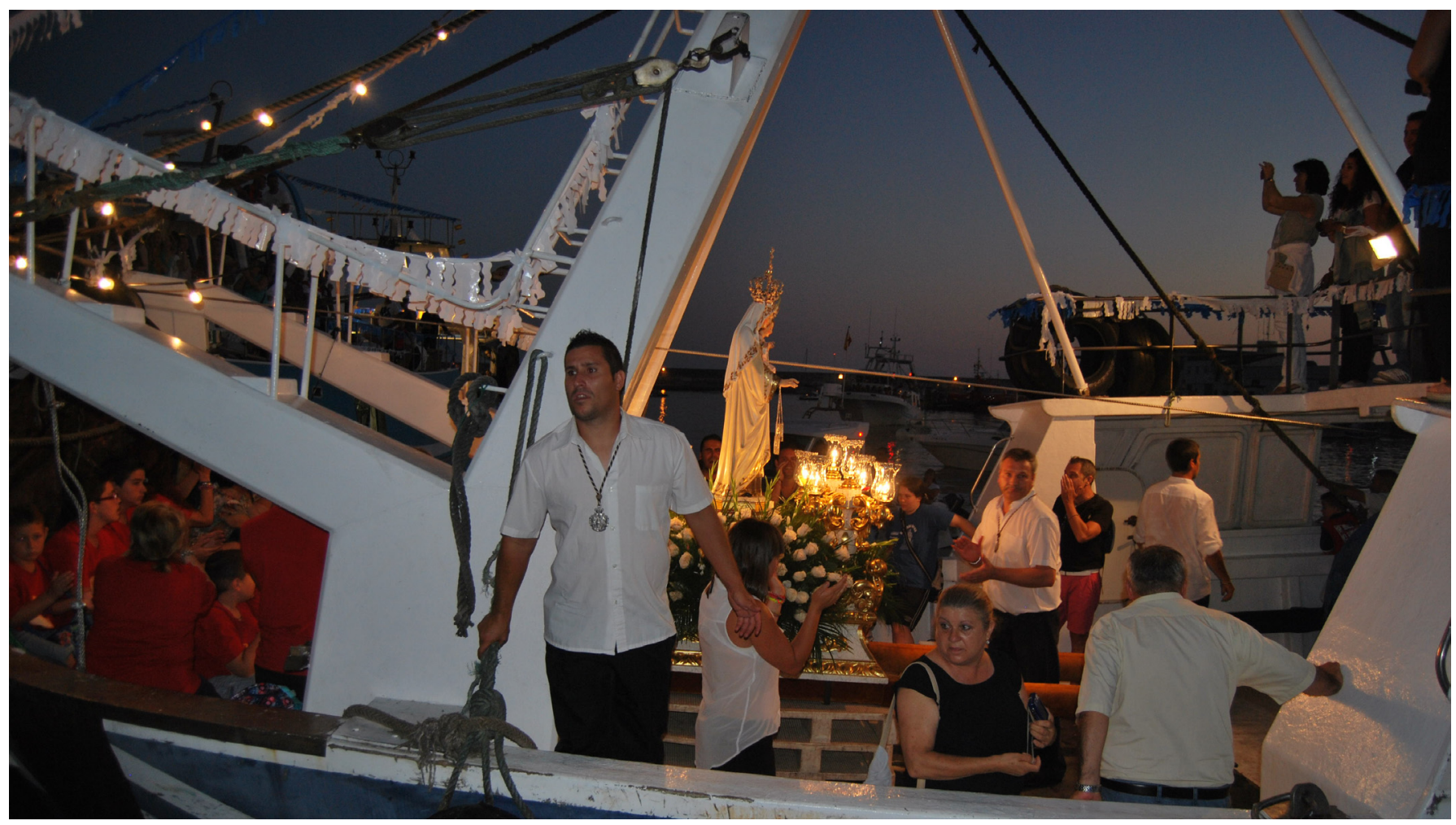

Ritual de la Virgen del Carmen en Motril

\section{BIBLIOGRAFÍA}

- La Cocina marinera de la Costa Tropical (2007) Granada: Observatorio del Mar, 2007

- FERNÁNDEZ MÁRQUEZ, M. (2007) Estudio sobre el impacto económico del puerto de Motril. Motril: Autoridad Portuaria de Motril, 2007

- El FIN de una cultura milenaria. Ciento cincuenta aniversario. Azucarera de Guadalfeo (2011) Granada: Universidad de Granada, Azucarera de Guadalfeo y Páginas de Espuma Editores, 2011

- SÁNCHEZ ESCOLANO, L. M.; ESPINOSA ARIAS, J. A. (2012) El binomio agricultura-turismo y su incidencia en el modelo territorial de la costa de Granada. Papeles de Geografía [en línea], n. ${ }^{\circ}$ 55-56, 2012, pp. 189-203. <http:// revistas.um.es/geografia/article/view/176301/148781> [Consulta: 26/02/2015]

- SÁNCHEZ SANCHEZ, F. J. (2009) El patrimonio arquitectónico azucarero en Andalucía Oriental. Intervenciones y nuevos usos. e-rph, revista electrónica de patrimonio histórico [en línea], n. ${ }^{0}$ 5, $2009<$ http:// www.revistadepatrimonio.es/revistas/numero5/concepto/ estudios/articulo.php> [Consulta: 26/02/2015]
- LACOMBA, J. A. (2005) La industria del azúcar en Andalucía en 1845. El informe de Ramón de la Sagra. Revista de Estudios Regionales [en línea], n. ${ }^{\circ}$ 7, 2005, pp. 295-315. <http://www.revistaestudiosregionales.com/ documentos/articulos/pdf831.pdf> [Consulta: 26/02/2015]

- GARCíA-ALLUT, A. (2004) La pesca artesanal, el cambio y la patrimonialización del conocimiento. PH Boletín del Instituto Andaluz del Patrimonio Histórico, n. ${ }^{\circ} 44,2004$, pp. 74-75. Recurso disponible en línea <http://www.iaph. es/revistaph/index.php/revistaph/article/view/1567/1567\#. VO8ccWNTdZk> [Consulta: 26/02/2015]

- díAZ GARcía, A. (1988) Documento árabe sobre "el Aduana del Açucar en Motril". En MALPICA CUELLO, A. El cultivo de la caña de azúcar en la costa de Granada en época medieval. Motril: Ayuntamiento, 1988

- DOMínguEz GARCíA, M. (1987) Azúcar e ingenios en Motril. Revista Cajasur, 1987

- PÉREZ VIDAL, J. (1971) Cañas y trapiches de azúcar en Marbella. Revista de Dialectología y Tradiciones Populares, tomo XXVII, cuadernos 3 y 4, 1971 